COMMENTARY

\title{
Pathways to the revitalization of Indigenous food systems: Decolonizing diets through Indigenous-focused food guides
}

\author{
Taylor Wilson ${ }^{\text {* }}$ \\ University of Winnipeg \\ Shailesh Shukla ${ }^{b}$ \\ University of Winnipeg
}

Submitted February 10, 2020 / Accepted February 11, 2019 / Published online June 12, 2020

Citation: Wilson, T., \& Shukla, S. (2020). Pathways to the revitalization of Indigenous food systems:

Decolonizing diets through Indigenous-focused food guides. Journal of Agriculture, Food Systems, and

Community Development, 9(4), 201-208. https://doi.org/10.5304/jafscd.2020.094.003

Copyright (C 2020 by the Author. Published by the Lyson Center for Civic Agriculture and Food Systems. Open access under CC-BY license.

\begin{abstract}
The 2019 Canadian Food Guide (CFG) was launched in January 2019 with a promise to be inclusive of multicultural diets and diverse perspectives on food, including the food systems of Indigenous communities. Some scholars argue that federally designed standard food guides often fail to address the myriad and complex issues of food security, well-being, and nutritional needs of Canadian Indigenous communities while imposing a dominant and westernized worldview of food and nutrition. In a parallel development, Indige-
\end{abstract}

a * Corresponding author: Taylor Wilson, Master's in Development Practice Candidate, University of Winnipeg; 599 Portage Avenue, 3RC060; Winnipeg, Manitoba, R3B 2G3, Canada; +1204-801-2378; taywilson260@gmail.com

b Shailesh Shukla, Department of Indigenous Studies, University of Winnipeg; 599 Portage Avenue, 3CR089; Winnipeg, Manitoba, Canada, R3B 2G3; s.shukla@uwinnipeg.ca nous food systems and associated knowledges and perspectives are being rediscovered as a hope and ways to improve current and future food security. Based on a review of relevant literature and our long-term collaborative learning and communitybased research engagements with Indigenous communities from Manitoba, we propose that Indigenous communities should develop their food guides considering their contexts, needs, and preferences. We discuss the scope and limitations of the most recent Canadian food guide and opportunities to decolonize it through Indigenous food guides, including their potential benefits in enhancing food security and well-being for Indigenous communities. We propose to design and pilot test

\section{Funding Disclosure}

We would like to acknowledge funding support from the Social Sciences and Humanities Research Council and the University of Winnipeg Research and President's office. 
such Indigenous food guides in communities Fisher River Cree Nation in Manitoba as community-based case study research that supports Indigenous-led and community-based resurgence and decolonization of food guides.

\section{Keywords}

Community-Based Research, Decolonial

Approach, Food Guide, Indigenous Food Security, Health, Indigenous Knowledge Systems, Nutrition, Self-Determination

\section{The Canadian Food Guide and its Limitations}

There have been many tools developed to address the food insecurity and well-being needs of the Canadian public, including Indigenous communities, such as the Canadian Food Guide (CFG). Health Canada (2019a) describes food guides as "basic education tools that are designed to help people follow a healthy diet," (p. 4) utilizing dietary analyses, data from surveys, and food supply and demand with the overall goal of translating nutritional science to a practical food choice. The guide is not only created to inform individuals on how to eat healthily, but also to help policymakers create policy and support programs related to food and nutrition in Canada.

\section{Brief History of the Canadian Food Guide}

The first Canadian Food Guide (CFG) was titled the Official Food Rules and was released in 1942. It was initially designed to prevent nutritional deficiencies due to food rationing from the War. The Official Food Rules identified six food groups at the time-milk, fruit, vegetables, cereals and bread, meat, and eggs —along with serving size suggestions. Since its inception, it has been made over several times to accommodate evolving sciencebased health and nutrition recommendations, social and economic fluxes, and the overall health statistics in Canada.

The revised version released in 2007, titled Eating Well with Canada's Food Guide, was created due to several factors including the rise in nutrition-related chronic diseases, findings from consultations with experts, focus testing, and the evolving food supply and demand chains. The same year, Health Canada released a parallel Indigenous version of the guide to address the growing Indigenous health issues related to food and nutrition, which failed to make any significant changes (Mundel, 2010). The 2007 Indigenous Food Guide (IFG) was produced in several Indigenous languages, including Anishinaabe, Plains Cree, Woods Cree, and Inuktitut. It also included depictions of several foods typically associated with Indigenous peoples in Canada, such as bannock, berries, wild game, and canned milk. This food guide aimed to engage Indigenous populations through schools and health facilities as well as developing policies that affect Indigenous peoples.

In 2019, Canada released the most recent version of the CFG with a new focus on plant-based proteins, lowering dairy intake, eating more fruits, vegetables, and whole grains, and drinking water. The 2019 CFG provides examples of different foods based on their recommendations, along with a visual representation of what a typical plate of food should look like (see Figure 1). There was no

\section{Figure 1. The 2019 Canadian Food Guide}

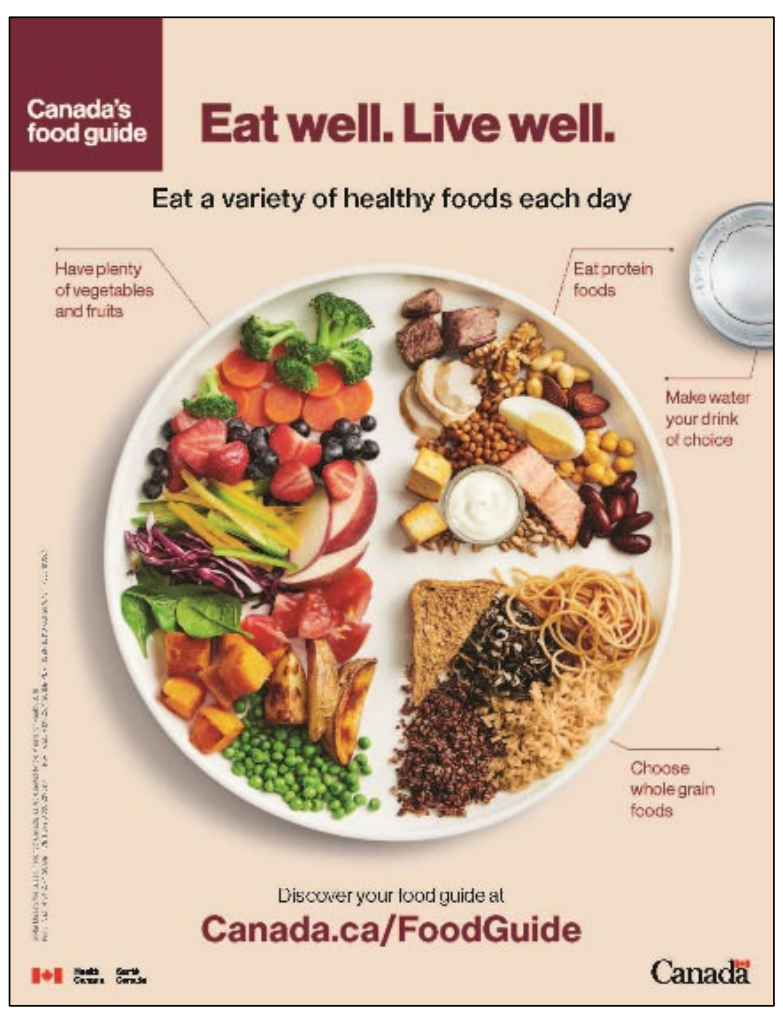

Source: Health Canada, 2019b. 
release of an IFG; instead, the guide was translated into several Indigenous languages.

\section{The Guide's Limitations}

The CFG is a one-size-fits-all model, designed to provide recommendations for healthy eating and food choices for all Canadians, with the user to interpret the recommendations to the best of their ability. The OSF model of the CFG does not represent the incredibly diverse population in Canada and does not tackle essential barriers to accessing healthy food, which leads to the marginalization of diets and food practices (Amend, 2017; Duignan, 2019). Amend $(2017$, p. 2) uses the example of many people of color, in which they assume their Indigenous or cultural foods are "unhealthy" because they are not represented in the guide. The Eurocentric ideals around healthy eating are often positioned in a scientific or unbiased way to "shield the document from outside influences deemed non-scientific" (Amend, 2017, para. 31), such as cultural food preferences.

Indigenous nurse Marie Martine stated that the guide would be difficult for people to use, especially those on low or fixed incomes, as many of the recommended foods are inaccessible due to food deserts within urban centers and Indigenous communities. One result of food deserts is that the prices of many of the recommended foods are higher than that of their unhealthy counterparts (CBC, 2007). The failure to combine or incorporate Indigenous food systems in food guides demonstrates the long history of Western and colonial food practices including how they have undermined Indigenous food systems, infringed on Indigenous peoples' livelihoods, and prevented their ability to self-govern and determine.

Damman, Eide, and Kuhnlien (2008) argue that the right to food and the right to culture go hand in hand for Indigenous peoples, which suggests that by providing both, you are providing the best possible solutions to counteract chronic diseases and food insecurity. When asked to address the issue, Mary Bush, the head of nutrition policy at Health Canada in 2007, argued that "creating many different food guides to address Canada's diverse ethnic and cultural groups was both impractical and unrealistic" (paraphrased in Amend, 2017, para. 10).
Health Canada (2019b) states that the 2019 food guide is essential for three reasons. The first is that what we eat influences our health, as our diets are a leading contributor to many chronic diseases like heart disease, cancer, and diabetes. The agency also mention that the burden of chronic disease varies across Canada, with Indigenous peoples in Canada facing a more significant burden than the general population. In its discussion around this reason, it also mentions that Indigenous peoples face a high number of barriers to manage those chronic diseases but offers no more on the subject. The second reason it is essential is that the food environment influences what we eat. Mostly, the foods available to us have a tremendous impact on what or how we eat. Health Canada does acknowledge the barriers Indigenous peoples face regarding food availability and Indigenous foods, but again offers nothing more on the subject. Ironically, it is here that it mentions that the constant stream of changing and conflicting messages around food can contribute to unhealthy eating, but does not mention how the guide contributes as well. The third reason behind the importance of the food guide is that supporting healthy eating is a shared responsibility; however, the guide takes no responsibility for supporting Indigenous health. It is the very reason that Health Canada deems the guide necessary, which are also limitations for Indigenous people in Canada.

The current CFG model also fails to consider the socioeconomic barriers to healthy food choices. Historically, the food guide and its revisions and recommendations over the last 60 years have been rooted in economic agendas such as pressure from the agriculture industry in Canada. Many of the recommendations made have "closely mirrored the interests of agricultural producers" (CBC, 2012). Nevertheless, it fails to consider the economic, social, and cultural barriers to accessing healthy foods. With the current discourse around reconciliation in Canada, CFGs, especially the most recent two (2007 and 2019), have failed to take into context the considerable barriers to accessing healthy foods. These include remote living, loss of land, loss of cultural traditions, lack of economic stability, and a myriad of issues stemming from colonization that Indigenous peoples face in gain- 
ing access to affordable and culturally relevant healthy foods.

Indigenous peoples in Canada represent unique perspectives and diverse knowledges regarding their Indigenous food systems (Kuhnlein et al., 2006; Shukla et al., 2019). In Indigenous cultures, these food systems go hand in hand with health and healing, and it is about time that these knowledge systems be nurtured because of their potential to have positive effects on Indigenous health, well-being, and food security. We argue that weaving local and Indigenous food systems and associated knowledges and perspectives in the development of a food guide can have many positive effects at local, national, and international scales for protecting food environments, restoring Indigenous foodways and cultures, improving food security and accessibility, and promoting local economies through community-based social enterprises.

\section{Braiding Indigenous Food Knowledge: A Tool for Food Sovereignty and Decolonization}

Traditional, Indigenous, or country foods (also known as Indigenous foods) are defined as those "from the local, natural environment [and that] are culturally acceptable" (Kuhnlein, \& Receveur, 1996, p. 417). The Indigenous food knowledges surrounding these foods include several culturally meaningful processes such as harvesting, processing, distributing, preparing, and moral teachings. It also involves spiritual and cultural factors that are incredibly important to Indigenous ways of being and make up cultural food preferences (Kerpen, Humbert, \& Henry, 2015). When creating food guides, it is crucial to incorporate these factors. Tabitha Robin (personal communication, January 29,2020 ) also stated that "the healthiest foods are the ones that have the most relationships." Culture influences attitudes and beliefs around food choices, and by incorporating healthy and culturally appropriate foods, food guides can affirm Indigenous cultures while also supporting healthy decisions. Healthy food lifestyles go beyond just healthy eating, and many Indigenous peoples associate Indigenous foods with the feeling of good health, so why not affirm those feelings (Kerpen et al., 2015; Raine, 2005; Willows, 2005)?

Discussions around food sovereignty in the food guide sector are in their early stages, which means that designing policies and programming in the food systems landscape is also challenging to do. There are so many areas of food policy that demand attention from this food sovereignty framework. However, there are still no practical examples of how to bring food sovereignty into the conversation in a sustainable way, especially when the discourse around Indigenous food systems is often separated from non-Indigenous or Western food systems (Desmarais \& Wittman, 2014).

Kekiewicz and Rotz (2018) observed over several years that the discourse of engagement between Indigenous peoples and settlers when developing food-related tools quickly resulted in a high level of discomfort that non-Indigenous peoples have while discussing Indigenous issues and food policies. When moving toward reconciliation in Canada, having difficult and uncomfortable conversations around colonial impacts and giving up power in order to have Indigenous inclusion and involvement is necessary to make progress. Creating spaces for this type of discourse allows for Indigenous self-determination and meaningful partnerships.

\section{Lessons from Indigenous Food Guides}

Many Indigenous communities and organizations are using Indigenous and decolonial approaches, and there are several that can act as inspiration for this Indigenous food system discourse. An example of an effective Indigenous food guide (IFG) can be found in Ligouri, Nassar, and Mehta's (2014) research around interactive nutrition guides (ING) in the United States. The ING is an online spreadsheet that suggests nutrient-rich Indigenous foods to make recipes, offers Indigenous alternatives for non-Indigenous ingredients, and provides nutritional information and local prices for the Indigenous ingredients. It offers Indigenous alternatives to Western ingredients so individuals can adopt Western recipes to fit their contexts. Liguori et al. (2014) argue that local and Indigenous foods "contribute to sustainable agricultural practices, encourage healthful eating, and sustain culturally relevant foods" (p. 4). They can also connect Indigenous 
peoples to their cultural food systems, encourage the community to holistically address health, and even protect local ecosystems.

Another example of an IFG comes from British Columbia, Canada, with the First Nation Health Authority (FNHA)'s Healthy Food Guidelines for First Nations Communities (2009). The goal of the guidelines is to address the nutritional environment through "modern choices that reflect traditional values such as giving, sharing, humility, wholeness, and land stewardship" (FNHA, 2009, p. 5). It provides suggestions for more cultural aspects of food consumption like feasts, large family meals, food sharing, and fundraisers. The most notable section of the FNHA (2009) guidelines is the section on improving local food security, and more specifically, on utilizing more local and regional foods. Unlike the ING, where they provide Indigenous alternatives to Western ingredients, the FNHA provides ways to incorporate healthy

\section{Figure 2. Fisher River Cree and English Cookbook, Traditional Cooking and Foods of Long Ago Gave Us Healthy Lifestyles and Helped Us to Live Long Lives}

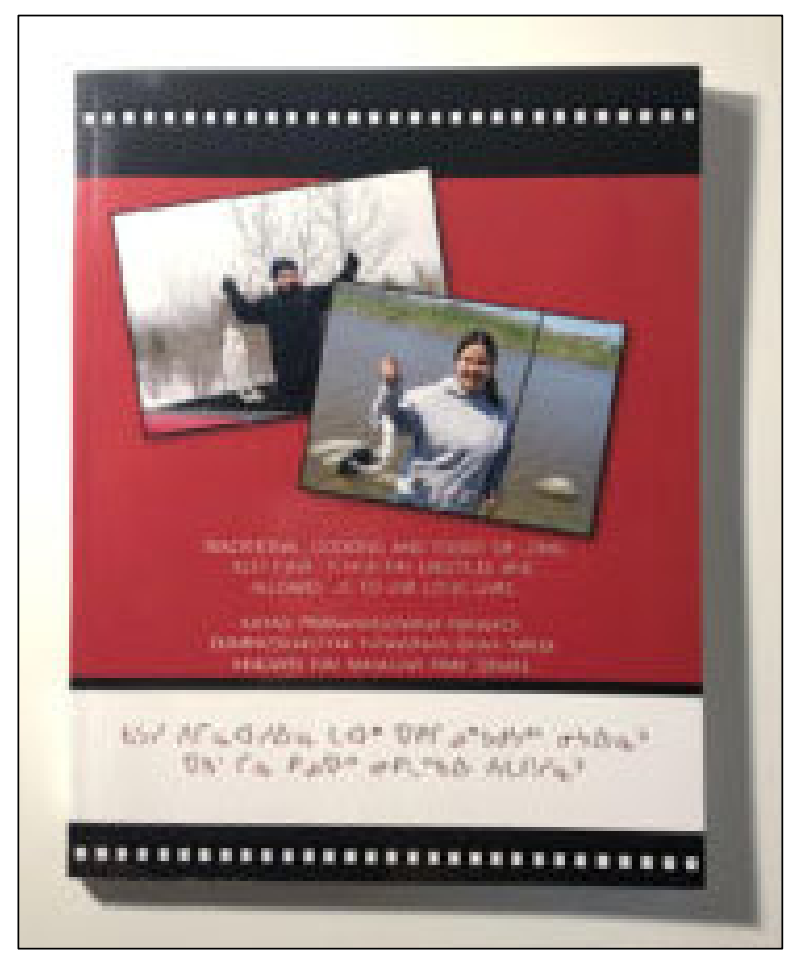

Published by Fisher River Cree Nation \& University of Winnipeg, 2019. ingredients from both Indigenous and Western traditions into one's diet.

In 2014, after noticing the epidemic of foodrelated chronic illnesses in the country, Brazil released its innovative new food guide, Dietary Guidelines for the Brazilian Population (BFG) (Ministry of Health of Brazil, 2015). The guide moved away from the typical food group and caloric measurements to a more Indigenous style of eating: unprocessed food that is grown in Brazil, eaten in shared food settings. Marion Nestle, an advocate for inclusive food policies, applauded the BFG as it is "based on foods that Brazilians of all social classes eat every day, and consider[s] the social, cultural, economic, and environmental implications of food choices" (Nestle, 2014, p. 1). Further, the emphasis on local foods and group meals aligns well with Indigenous foodways and eating practices (Dawson, 2020).

In late 2019, community members of Fisher River Cree Nation (FRCN), in partnership with the University of Winnipeg, released the FRCN cookbook Traditional Cooking and Foods of Long Ago Gave Us Healthy Lifestyles and Helped Us to Live Long Lives (see Figure 2) (FRCN, 2019; FRCN \& University of Winnipeg, 2019). The cookbook consists of 69 Indigenous recipes and highlights dozens of Indigenous foods practices within the community. It shares land-based stories of the teachings behind the recipes, underscoring the importance of Indigenous foods and associated values. For example, quotes in the cookbook share important values of the community, including food sharing: "as my mom used to say ... when they were growing up; they'd share a moose among the community" (p. 21); respect for the animal and environment: "when I eat wild meat it helps me think about our food, it helps me respect the animal" (p. 28); and serving size and food preparation: "we used to eat fish two or three times a day, it was never fried ... it was healthier that way" (p. 40) (FRCN, 2019). The book also provides a Cree syllabic translation of each page, so the cookbook can then be used as more than a food and recipe book in the kitchen; but it can be moved into the classroom as a language and educational tool for Cree food culture revitalization. 
Toward Indigenous-led Food Security Innovation: Fisher River Cree Nation's Indigenous Food Guide

At this point, international approaches to Indigenous food guides and food systems, like those being undertaken in Canada, are relatively new, although there are several that are promising. However, with so many approaches being new and attempting to break the realm of Indigenous-led frameworks, it is hard to pinpoint what is a wise practice suited in one community context.

Contemporary nutritional sciences are beginning to acknowledge the importance of Indigenous food practices as a key to health, well-being, and Indigenous cultural revitalization and resurgence. There is also an emerging opportunity and need to learn from the underlying Indigenous food knowledges and perspectives that give rise to Indigenous food systems and associated knowledges.

An Indigenous food guide specific to each diverse Indigenous group is a way for these communities to be empowered, work on community development, be self-sustaining, and improve their knowledge of nutrition in relation to their cultural food systems. It is a way for these communities to address accessibility and affordability in ways that are self-determining, creative, and relevant to their contexts.

Indigenous food knowledges and perspectives are central and critical in the debate and practice of the current and future of Indigenous food security and sovereignty. The first author of this commentary, who is an Ojibwe-Cree woman born and raised in FRCN along the southwestern shores of Lake Winnipeg, intends to design an Indigenous food guide uniquely suited to the needs, preferences, voices, perspectives and Indigenous food knowledges of FRCN community members for current and future generations. The FRCN food guide (see Figure 3) will be developed through

\section{Figure 3. Food Guide Framework, Compiled by the Authors}

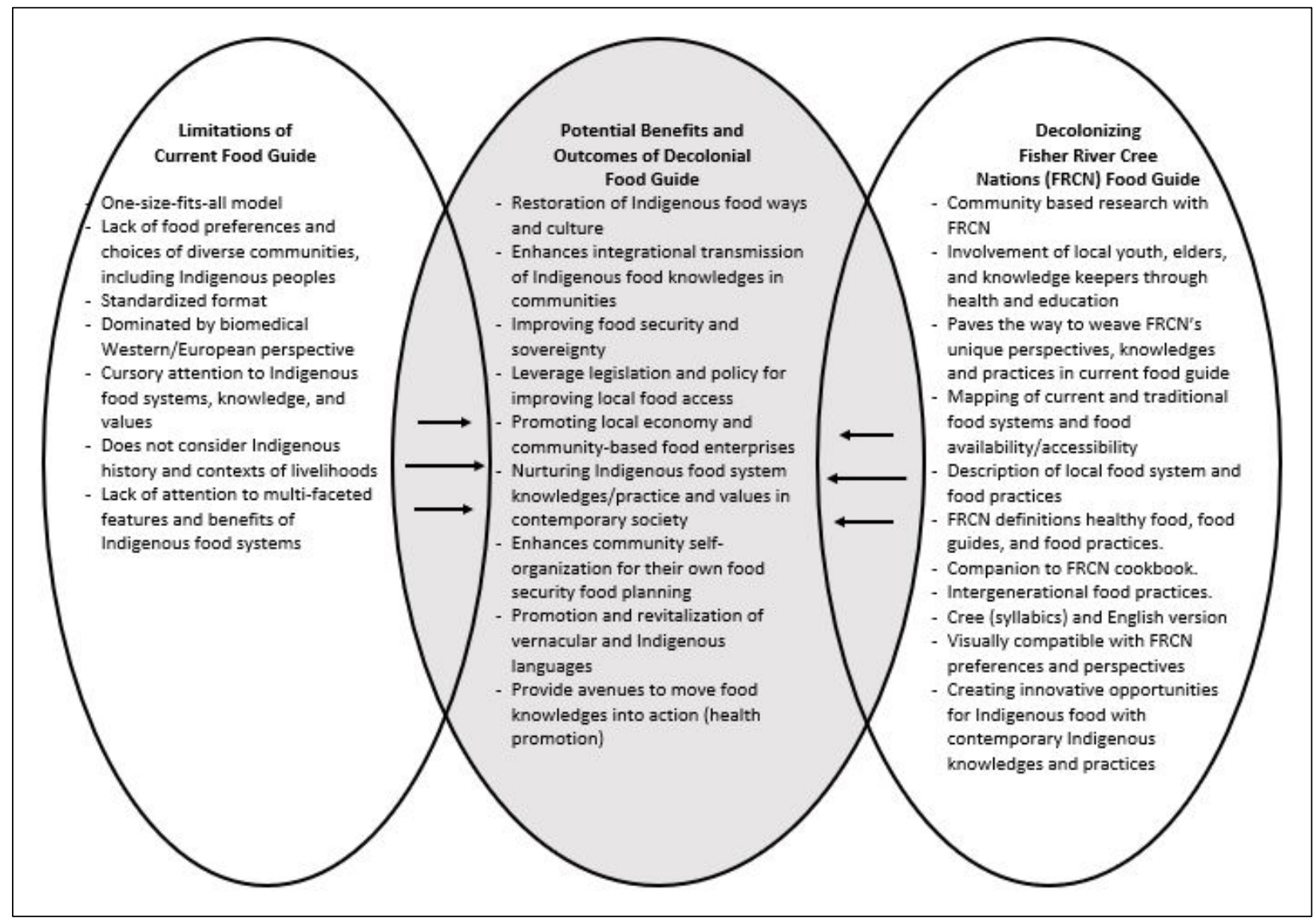


community-based and -led collaborative research with the active involvement of youth and knowledge-keepers, and will follow the model of a wise practices approach that addresses the limitations FRCN community members have in making healthy food choices, accessing healthy and Indigenous foods, and sustainably revitalizing their cultural food practices. The FRCN food guide will build on the long-term partnership and experiences of the University of Winnipeg and will use the cookbook recipes as a starting point. We hope that the lessons from this small-scale, wise practicebased Indigenous food innovation will inspire similar Indigenous food guides in Turtle Island, and elsewhere, and will enrich the debate and practice of current and future food security by privileging the perspective, visions, and voices of local Indigenous communities.

\section{Acknowledgment}

We are grateful to Fisher River Cree Nation for their continued support and collaboration.

\section{References}

Amend, E. (2017). My food guide, their food guide: Diversity and personalization in Canada's national dietary guidelines. Cuizine: The Journal of Canadian Food Cultures, 8(1). https://doi.org/10.7202/1046624ar

CBC. (2007, April 12). First aboriginal food guide balances traditional, practical. CBC. Retrieved from https://www.cbc.ca/news/canada/north/first-aboriginal-food-guide-balances-traditional-practical-1.637849

CBC. (2012, July 30). The politics of food guides. CBC. Retrieved from https://www.cbc.ca/news/health/the-politics-of-food-guides-1.1268575

Damman, S., Eide, W. B., \& Kuhnlien, H. V. (2008). Indigenous peoples' nutrition transition in a right to food perspective. Food Policy, 33(2), 135-155. https://doi.org/10.1016/i.foodpol.2007.08.002

Dawson, L. (2020). "Food will be what brings the people together": Constructing counter-narratives from the perspective of Indigenous foodways. In P. Settee \& S. Shukla (Eds). Indigenous Food Systems: Concepts, Cases, and Conversations (pp. 83-100). Toronto: Canadian Scholars Press.

Desmarais, A. A., \& Wittman, H. (2014). Farmers, foodies and First Nations: Getting to food sovereignty in Canada. Journal of Peasant Studies, 41(6), 1153-1173. https://doi.org/10.1080/03066150.2013.876623

Duignan, S. (2019, January 17). Canada's new food guide: A fail on culture and sustainability. The Conversation. Retrieved from http://theconversation.com/canadas-new-food-guide-a-fail-on-culture-and-sustainability-109718

First Nations Health Authority (FNHA). (2009). Healthy food guidelines for First Nations communities. First Nations Health Authority. Retrieved from https://www.fnha.ca/Documents/Healthy Food Guidelines for First Nations Communities.pdf

Fisher River Cree Nation. (2019, December 19). Fisher River Cree Nation English-Cree cookbook now available [News release]. University of Winnipeg News Centre. Retrieved from https://news-centre.uwinnipeg.ca/all-posts/fisher-river-cree-nation-english-cree-cookbook-now-available/

Fisher River Cree Nation \& University of Winnipeg. (2019). Traditional cooking and foods of long ago gave us healthy lifestyles and helped us to live long lives (Fisher River Cree-English Cookbook). Manitoba: Fisher River Cree Nation.

Health Canada. (2019a). History of Canada's food guides from 1942 to 2007. Health Canada. Retrieved from https://www.canada.ca/content/dam/hc-sc/documents/services/food-nutrition/canada-foodguide/resources/evidence/food-nutrients-health-interim-evidence-update-2018/26-18-2165History $\% 20$ of $\% 20$ CFG-EN-06.pdf

Health Canada. (2019b). Canada's dietary guidelines. Retrieved October 2, 2019, from https://food-guide.canada.ca/en/guidelines/

Kekiewicz, L., \& Rotz, S. (2018). Toward anti-colonial food policy in Canada? (Im)possibilities within the settler state. Canadian Food Studies, 5(2), 13-24. https://doi.org/10.15353/cfs-rcea.v5i2.202

Kerpen, S. T., Humbert, M. L., \& Henry, C. J. (2015). Determinants of diet for urban aboriginal youth: Implications for health promotion. Health Promotion Practice, 16(3), 392-400. https://doi.org/10.1177/1524839914557862

Kuhnlein, H., Erasmus, B., Creed-Kanashiro, H., Englberger, L., Okeke, C., Turner, N., Allen, L., \& Bhattacharjee, L. (2006). Indigenous peoples' food systems for health: Finding interventions that work. Public Health Nutrition, 9(8), 1013-1019. https://doi.org/10.1017/PHN2006987 
Kuhnlein, H. V., \& Receveur, O. (1996). Dietary change and traditional food systems of Indigenous peoples. Annual Review of Nutrition, 16, 417-442. https://doi.org/10.1146/annurev.nu.16.070196.002221

Liguori, K., Nassar, A., \& Mehta, K. (2014, October). An interactive nutritional guide for developing low-cost healthy meals while maintaining Indigenous foods. Presentation at the Global Humanitarian Technology Conference, San Jose, California. Retrieved from https:// sites.psu.edu/hese/2016/03/16/an-interactive-nutritional-guide-for-developing-low-costhealthy-meals-while-maintaining-indigenous-foods/

Ministry of Health of Brazil. (2015). Dietary guidelines for the Brazilian population. Ministry of Health of Brazil. Retrieved from http://bvsms.saude.gov.br/bvs/publicacoes/dietary guidelines brazilian population.pdf

Mundel, E., \& Chapman, G. E. (2010). A decolonizing approach to health promotion in Canada: The case of the Urban Aboriginal Community Kitchen Garden Project. Health Promotion International, 25(2), 166-173. https://doi.org/10.1093/heapro/daq016

Nestle, M. (2014, February 19). Brazil's new dietary guidelines: Food-based! [Blog post]. Food Politics. Retrieved from https://www.foodpolitics.com/2014/02/brazils-new-dietary-guidelines-food-based/

Raine, K. D. (2005). Determinants of healthy eating in Canada: An overview and synthesis. Canadian Journal of Public Health, 96(3, Suppl.), S8-S15. https://doi.org/10.1007/BF03405195

Shukla, S., Alfaro, J., Cochrane, C., Garson, C., Mason, G., Dyck, J., Beaudin-Reimer, B., \& Barkman, J. (2019). Nimíciwinán, nipimátisiwinán — "Our food is our way of life": On-Reserve First Nation perspectives on community food security and sovereignty through oral history in Fisher River Cree Nation, Manitoba. Canadian Food Studies, 6(2), 73-100. https://doi.org/10.15353/cfs-rcea.v6i2.218

Willows, N. D. (2005). Determinants of healthy eating in Aboriginal peoples in Canada: The current state of knowledge and research gaps. Canadian Journal of Public Health, 96(3, Suppl.), S36-S41. https://doi.org/10.1007/BF03405199 